\title{
Application of Interaction Effect Among Students in Classroom Teaching Based on the Decision Tree
}

\author{
Dong Xie \\ Foreign Language College, Civil Aviation Flight University of China, Guanghan, China \\ xie_d_ong1@126.com
}

Keywords:decision tree;interaction among students; english class: empirical analysis; optimization

\begin{abstract}
English teaching in the classroom is an important part of the whole link of English learning and the key to guide students to use and express English correct in work, study and life. This paper integrates the top-down mechanism of decision tree with interaction effect of students based on extensive practical experience and research experience and the actual investigation in the field of English teaching. This paper first analyzes the advantages of integration of both in the English classroom teaching. It uses the idea of mathematical model to analyze the English classroom teaching. It proposes to build an optimization model based on interaction effect among students of decision tree in the English classroom teaching which provides a theoretical basis and practical guidance ideas for research in the field in a certain extent.
\end{abstract}

\section{Introduction}

With the deepening of education reform, the research of English classroom teaching is the hot spot in recent years. The interaction effect among students is a teaching method which is the most promising method currently[1]. It interacts among students only focusing on the teaching content in the actual teaching process. It not only reflects the subjectivity of students but also improves students' ability of reading, writing and speaking and enhances the learning enthusiasm and interest in learning English. It plays subjectivity of students more efficient in the classroom which embodies high efficiency of English teaching of mutual exchange[2]. Generally speaking, the English classroom teaching should combine with practical teaching and teach students based on the actual levels of the students.

\section{Overviews of decision tree and the educational philosophy of the interactions among students}

A. Teaching philosophy of the decision tree

In a decision tree, there are a lot of decision-making groups. There are a lot of decision-making members in each decision-making group which is called decision set. The specific is shown as follows:

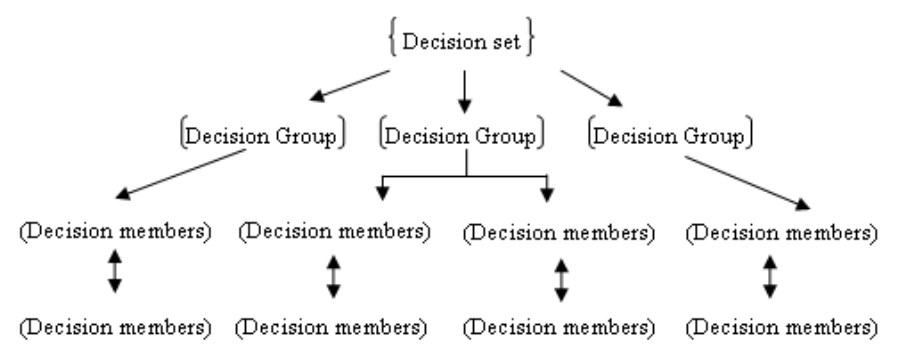

Figure 1. Teaching philosophy diagram based on decision tree

In Figure 1, every decision set is completed by teachers. They record the potential observations of students in actual teaching and take the constant corrective measures to students tend to positive state constantly in the process of learning English. They make the maximum decision for the change of students. They get individual characteristics variables of students.

B. Teaching philosophy of interactive effects among students

We should pay attention to the five elements of the interactive effects among students in the teaching process which are shown in the following diagram. 


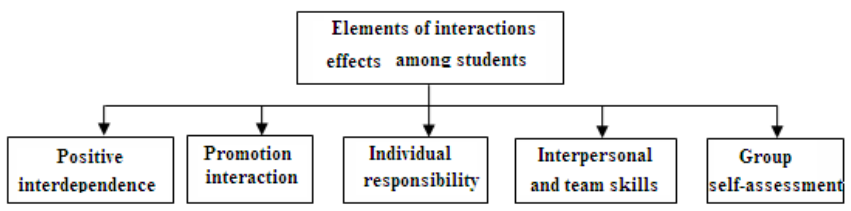

Figure 2. Five elements of the interactive effects among students

As is shown in Figure 2, we should pay attention to the relationship among the teachers and students when run interaction effects among students. Positive dependence among individual students in the classroom learning process is mainly referred to the dependence of English learning and interaction. In the English classroom learning, teachers can interact with students face-to-face according to the needs of teaching and promote the communications among students and teachers and students and students. The students can feedback the information to the teachers timely.

\section{Analyses of integrative advantages of decision tree and interaction effects in English classroom teaching}

The decision tree and interaction effect are classroom learning processes which units are group in English classroom teaching. They can improve the team consciousness of whole learning process and strengthen the communication among team members and make students to help each other and participate in the communication and achieve the common goal as a personal goal which makes the classroom atmosphere of whole English teaching more harmonious[3]. For example, teaching data vector $\mathrm{X}$ of a English article of a unit was assigned to a few known category groups $1, \ldots, \mathrm{k}$. Unit English article teaching $\mathrm{X}$ was completed by m students. So:

$$
\mathrm{X}=[\mathrm{x}(1), \mathrm{x}(2), \ldots, \mathrm{x}(\mathrm{m})]
$$

Through the formula (1) and the above introduction of decision tree, each of the students' learning status has a feature vector in English classroom teaching. Its characteristic value is the same as data vector-valued $X$ of the whole class. All of them are influenced by the teachers. We should pay attention to the role interaction of teacher and students which specific is shown as follows:

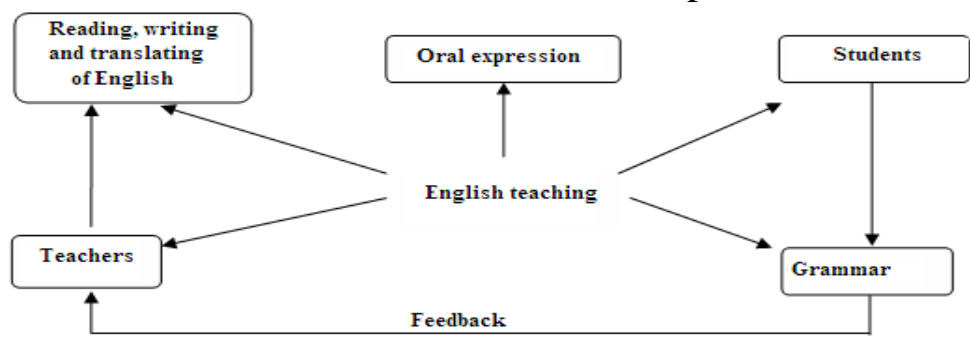

Figure 3. Decision tree and interaction effects in the English classroom teaching model

As is shown in Figure 3, due to the academic records and learning abilities of students and different, we should pay attention to the parameters of the individual characteristics when build the decision tree and students interaction effects among students. In a classroom or a school term, English learning performance of the entire Student groups is a continuous and random process[4]. Decision tree is also changes random, so teachers occupied a very important position in summary of teaching.

During the discussion and appraisal of a panel, we should first test the probability $\mathrm{P}_{i}$ which corresponding to the learning group $\mathrm{i}$. the conditional probability density function $\mathrm{P}(\mathrm{x} \mid \mathrm{i})$ of learning group corresponding to every learning number $\mathrm{i}$ and class whole vector point $\{\mathrm{X}\}$ of teachers observation space. Teachers usually can classify observation data of students in the classroom according to the maximize probability inspection. In other words, empirical probability according to the observation of teachers and the students' self evaluation is i. Probability test value of $i$ is the largest. The student individual and team observed data vector $\mathrm{X}$ are divided into class I, so,

$$
P[\mathrm{i} \mid \mathrm{x}] \quad \mathrm{P}[\mathrm{j} \mid \mathrm{x}] \text {,to every } \mathrm{j} \quad(1,2, \ldots, \mathrm{k})
$$

In function (2), according to the Bayes theorem of mathematical theory of probability, we can know that posterior probability can be expressed as a function which is made up by prior probability function and conditions density function. It can be expressed as[13]: 


$$
p\left[w_{j} \mid x\right]=\frac{p\left(x \mid w_{j}\right) p_{j}}{\sum_{i=1}^{k} p\left(x \mid w_{i}\right) p_{i}}, \mathrm{j} \quad(1,2, \ldots, \mathrm{k})
$$

In function (3), denominator the right side of equal sign has no relevance with $j$. Decisive factor of function (2) can be processed according to the molecule in the right side of equal sign of formula (3). Molecular is related with all js. In other words, in the whole English teaching, teacher plays a role of guide and summary. Class data vector $\mathrm{X}$ of English teaching class belongs to class $\mathrm{i}$. So,

$$
P(x \mid \text { i) } \operatorname{PkP}(x \mid j) P j, j \quad(1,2, \ldots, k)
$$

The decision tree integrates with interaction effects in English classroom teaching. The decision depends on the statistical performance of interactions among students and the ability of English to express all data changes which include multidimensional data space of all the observation data. So, the whole classroom teaching can stimulate the study enthusiasm of students and encourage the poor student to build the confidence which can reflect the subjectivity of every student and play the advantage of English classroom teaching in English learning of students effectively.

So, in the decision of English classroom teaching, the student individual variables can be observed and corrected which can judge the comprehensive performance of students[5]. For the student, it has a fair and reasonable learning space, and for the teacher, it can decide English teaching scientific. In the actual teaching process, we can apply the relationship of students to establish mathematical function model to decide the whole English classroom teaching.

\section{Optimization interaction effect English classroom teaching model based on decision tree}

A.Model analysis

Optimization interaction effect English classroom teaching model based on decision tree aims at stimulating the learning enthusiasm of students[6]. In the teaching practice, it discovers method of teaching and thinking which is novel, unique and innovative. It continuously breaks through the old mode of teaching and thinking. It fosters innovative English learning thinking of students based on the cultivation of the students' innovation consciousness and ability of English learning.

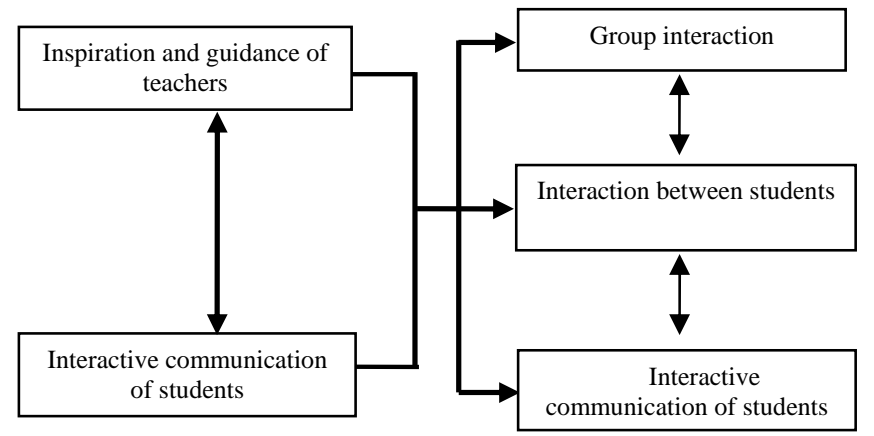

Figure 4. Optimization interaction effect English classroom teaching model based on decision tree

As is shown in Figure 4, in the English classroom teaching mode which based on the decision tree and interaction effect, the teacher measures the learning attributes of students according to information gains of students. In other words, the teacher treats the overall change after the teachers' guidance and communications among students as nodes to measure student learning attributes. In the process of teaching, it should stimulate divergent thinking of student to learn English. In the process of learning, the students are not restricted by traditional methods[7]. They can find the answers from multi-faceted, multi-angle, multi-level when encounter problems.

The reason why we summaries the decision tree in a decision tree is the entire English learning is a random and recursive process. So, we should summaries the members of the entire team through the calculation of Information entropy of every team. Learning group in the classroom can be composed of 3-5 students. The teams, the members, the teachers and teachers and students can interact with each other to study learning behavior of each individual. So, the information entropy can be expressed as[8]:

$$
I(U)=-\sum_{i} P\left(u_{i}\right) \log _{2} P\left(u_{i}\right)
$$

The probability tree of different students is[18]: 


$$
P\left(u_{i}\right)=\frac{\left|u_{i}\right|}{|S|}
$$

Therefore, the important points of the optimization interaction effects English classroom teaching model based on the decision tree are interactive import and interactive innovation. The teachers set up the profiles of the classroom teaching and registered learning goals interacted with students about the teaching dynamic factors. The teachers inspire and guide students to practice and communicate with each other through the interaction among students and teachers. Teachers set up exercises to train the practical ability of students. The students complete interactive innovation by communicating with each other in the learning process and to achieve the purpose of teaching through the feedback and self-building.

B.Empirical analysis of model

Teachers build the following model in English grammar teaching of the classroom teaching which is shown as follows[9]:

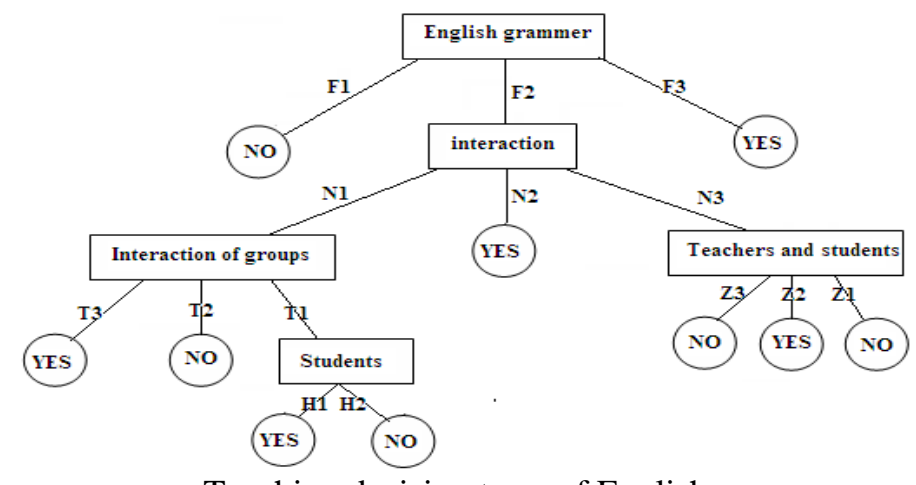

Figure 5. Teaching decision trees of English grammar

As is shown in Figure 5, in order to get the maximum of the interaction effects in the learning of English grammar by motivating students, we should clear know the motivation of English grammar learning and encourage students to develop their own Innovative thinking and act of English and understand the power of teachers formed in the teaching process. We also should stimulate and improve the students to achieve their learning goals through a combination of internal and external. $|S|$ is the total number of examples set S of English grammar. $\left|u_{i}\right|$ is the example number of English grammar class ui . We can define English grammar learning of a lesson as a process to mobilize learning enthusiasm of students. In other words, we can guide the students to learn English grammar repeatedly through the development of innovative thinking and enhancement of academic performance targets. Therefore, conditional entropy can be expressed as[10]:

$$
I(U / V)=-\sum_{j} P\left(v_{j}\right) \sum_{i} P\left(u_{i} / v_{j}\right) \log _{2} P\left(u_{i} / v_{j}\right)
$$

There is an ability which can not only remain or change the way of thinking and learning of students but also can play and the potential learning ability of every student in the class completely. When the attributes $\mathrm{X}$ choice $v_{j}$, the probability of $v_{j}$ is as follows[11]:

$$
P\left(v_{j}\right)=\frac{\left|v_{j}\right|}{|S|}
$$

The essence of English grammar learning is to affect students' learning behaviors by influencing students' learning needs and motivation. It is a strengthening process of students in English lessons. The conditional probability of the student's class ui is as follows:

$$
P\left(u_{i} / v_{j}\right)=\frac{\left|u_{i}\right|}{\left|v_{j}\right|}
$$

The learn appetence of student dominates the learning behaviors of students in English lessons. The motivation produced in the learning needs which need the subjective experience of students in English lessons. It is the necessarily reflection of the learning needs in English classroom. Information gain value[12]: 


$$
\operatorname{Gain}(X, S)=I(U)-I(U \mid V)
$$

Therefore, we should analyze optimization interactive effects of English classroom teaching which based on decision tree using the function. We also should build decision tree nodes, and mark the student attributes and divide them so that it can change thinking and learning ways in the process of English learning. We should improve the quality of teaching and strengthen the effectiveness of teaching at the same time. In the process of application and practical, we should emphasis spatial interactions of teachers-students and students-students. In the use of teaching dynamic factors, we should integrate teaching into learning.

\section{Conclusion}

In English classroom teaching, the more important is to cultivate awareness of English learning and positive spirit of the students, and to motivate the spirit of innovation, questioning and criticism of students in English learning process, and to explore students' English ability to think independently and behavior understand and expression ability which full of individuals characteristics using new English learning method and thinking mode so that it can integrate effective factors to inspire learning teaching enthusiasm and improve the practical ability in the implementation of a new method.With the advancement in networking and multimedia technologies enables the distribution and sharing of multimedia content widely. Insuring the copyrighted multimedia content is appropriately used has become increasingly critical. Once a piece of digital content is decrypted, the dishonest customer can redistribute it arbitrarily.

\section{References}

[1] Hansun Zhang Waring, Barbara L. Hruska, "Getting and keeping Nora on board: A novice elementary ESOL student teacher's practices for lesson engagement” ,Linguistics and Education, Vol.22, No.4, 2011, pp.441-455.

[2] Samy A. Azer. "Problem-based learning in the fifth, sixth, and seventh grades: Assessment of students' perceptions”, Teaching and Teacher Education, Vol.25, No.8, 2009,pp.1033-1042.

[3] Maxine Eskenazi, “An overview of spoken language technology for education”, Speech Communication, Vol.51,No.10, 2009,pp.832-844.

[4] Siu Cheung Kong, Wing Mui Winnie So, “A study of building a resource-based learning environment with the inquiry learning approach: Knowledge of family trees”, Computers \& Education, Vol.50, No.1, 2008, pp.37-60.

[5] Yueh-Min Huang, Po-Sheng Chiu, Tzu-Chien Liu, Tzung-Shi Chen, "The design and implementation of a meaningful learning-based evaluation method for ubiquitous learning”, Computers \& Education, Vol.57, No.4, 2011,pp.2291-2302.

[6] Bernard Montoneri, Tyrone T. Lin, Chia-Chi Lee, Shio-Ling Huang, “Application of data envelopment analysis on the indicators contributing to learning and teaching performance", Teaching and Teacher Education, Vol.28, No.3, 2012,pp.382-395.

[7] Hansun Zhang Waring, Barbara L. Hruska, "Problematic directives in pedagogical interaction”, Linguistics and Education, Vol.23, No.3, 2012,pp.289-300.

[8] Einat Heyd-Metzuyanim, Anna Sfard, "Identity struggles in the mathematics classroom: On learning mathematics as an interplay of mathematizing and identifying", International Journal of Educational Research, Vol.51-52, 2012,pp.128-145.

[9] Michele Schweisfurth, "Learner-centred education in developing country contexts: From solution to problem? ”,International Journal of Educational Development, Vol.31, No. 5, 2011, pp.425-432.

[10] Anne Feryok, "Language teacher cognitions: Complex dynamic systems? ”, System, Vol.38, No.2, 2010, pp.272-279.

[11] Chia-Chen Chen, Tien-Chi Huang, "Learning in a u-Museum: Developing a context-aware ubiquitous learning environment”, Computers \& Education, Vol.59, No.3,2012,pp.873-883.

[12] Dursun Delen, “ A comparative analysis of machine learning techniques for student retention management”, Decision Support Systems, Vol.49,No.4, 2010,pp.498-506. 